\title{
Pensiones en Costa Rica: Mitos, verdades e interrogantes
}

Recibido: 13 de abril 2018 Revisado: 15 de agosto 2018 Aprobado: 5 de setiembre 2018

Andrey Badilla Solano Costarricense. Magister en Estudios Latinoamericanos con énfasis en cultura y Desarrollo de la Universidad Nacional de Costa Rica, Licenciado en Ciencias Políticas por la Universidad de Costa Rica, Investigador del Centro de Investigación en Cultura y Desarrollo de la Universidad Estatal a Distancia de Costa

Rica. Investigador principal de informe de investigación:

Orígenes políticos y económicos de la crisis de la CCSS. Interesado en temas sobre Estado de Bienestar, Seguridad Social, políticas públicas y complejidad. Correo electrónico: abadillas@uned.ac.cr

\section{Stephanie Ramírez Flores} Costarricense. Bachiller en Sociología y estudiante de la Licenciatura en Sociología por la Universidad Nacional de Costa Rica. Realizó su Praćtica Profesional Dirigida en el Centro de Investigación en Cultura y Desarrollo de la Universidad Estatal a Distancia de Costa Rica y tiene interés en el campo de la Sociología Criminal. Correo electrónico: stephanieramirezflores95@hot
Resumen: En este artículo el lector encontrará una discusión sobre los impactos de los cambios en el perfil demográfico del país, el problema estructural del empleo durante el Proyecto Histórico Neoliberal, el problema fiscal del país y la base tributaria insuficiente, la gestión de la administración y los mecanismos de control interno sobre el Seguro de Pensiones de la Caja Costarricense del Seguro Social desde una perspectiva crítica.

Palabras clave: CCSS, Seguro de Pensiones, RIVM, Estado de bienestar

\section{Pensions in Costa Rica: Myths, Truths and Questions}

Abstract: In this paper the reader will find a discussion on the impacts of the changes in the demographic profile of the country, the structural problem of employment during the Neoliberal Historical Project, the fiscal problem of the country and the insufficient tax base, the management of the administration and the mechanisms of internal control over the Pension Insurance of the Costa Rican Social Security Fund from a critical perspective.

Key words: Social Security, Pensions, Welfare State, CCSS 


\section{Introducción}

El presente artículo se deriva del informe de investigación titulado: Orígenes políticos y económicos de la crisis de la CCSS, elaborado en el Centro de Investigación en Cultura y Desarrollo de la Universidad Estatal a Distancia de Costa Rica. En este sentido y como su nombre lo indica, el informe contiene una intención general y explicativa, por ende, hemos decidido profundizar en componentes y variables que participan de la actual crisis del sistema de pensiones Régimen de Invalidez, Vejez y muerte (RIVM de ahora en adelante). Este se distingue de otros trabajos relacionados con el Seguro de Pensiones, que, aunque no será abordado en este artículo, plantea una aproximación compleja (una introducción al estudio de la seguridad social, desde una aproximación compleja se plantea en el subapartado del informe: ¿Debe la crisis de la CCSS ser estudiada desde una perspectiva compleja?, así como en un artículo en proceso de publicación: La complejidad en el estudio de los sistemas de seguridad social), así como la triangulación de datos elaborados por la Dirección Actuarial de la CCSS al año 2017 y el estado de la cuestión más actualizado posible. Merece especial alusión los trabajos elaborados por Martínez Franzoni (2017); Martínez Franzoni y Sánchez-Ancochea (2016); y ANEP (2017).

EI RIVM nace en el año 1947, con dos reformas importantes. En el año 1971, adquiere sentido universal al facultarse para cubrir a las personas trabajadoras del país y, en 1975, asume al Régimen de Pensiones no Contributivo. Estas dos reformas le dan su actual estructura. El sistema es de capitalización, es decir, se contribuye a una bolsa común de acumulación que permite dos beneficios: 1) el derecho a jubilación por parte de quien trabaja y que haya alcanzado el número de cuotas y la edad actual de jubilación 65 años (en años anteriores se permitieron jubilaciones adelantadas, en promedio a los 62 años), cuyo tope máximo es de $\mathbb{l} 1500$ 000; y 2) un subsidio del Estado para aquellas poblaciones en condición de vulnerabilidad por razones de invalidez, vejez o muerte o que no contribuyeron al régimen por razones de pobreza o indigencia, que forman parte del Régimen de Pensiones no Contributivo y que reciben una pensión mínima de $\mathbb{L} 78000$ al mes con derecho a aguinaldo y al seguro de salud.

Al igual que cualquier otro sistema de pensiones en el mundo, este enfrenta retos. En el caso costarricense, estos podrían entenderse a partir de la interrelación de, al menos, las siguientes variables:

- El cambio en el perfil demográfico del país.

- El problema estructural del empleo durante el Proyecto Histórico Neoliberal (sobre el que volveremos más adelante).

- El problema fiscal del país y la base tributaria insuficiente, este, como veremos en párrafos posteriores, utiliza distintas herramientas y artilugios de financiamiento de su propia deuda. 
- La gestión de la administración y los mecanismos de control interno.

\section{Cambios en el perfil demográfico}

Costa Rica ha consolidado una serie de políticas sociales y de salud que le han permitido al país condiciones de vida comparables con los estándares internacionales más altos. Por ejemplo: la tasa de mortalidad infantil, la expectativa de vida y la prácticamente erradicación de enfermedades prevenibles, mediante un programa de vacunación universal y solidario.

En el caso de las pensiones, las variables entorno a la expectativa de vida, la tasa de natalidad y fecundidad son determinantes por el siguiente motivo: el actual sistema de pensiones depende de las contribuciones tripartitas del Estado, de los trabajadores y de los patrones, aunque sobre estos últimos recae el mayor peso (los patronos contribuyen un 5,08\%, los trabajadores 3,84\% y el Estado 0,58\%), quienes aportan a un sistema de capitalización solidario, al cumplir cierta cantidad de cuotas o al cumplir la edad mínima de jubilación, tienen el derecho de retirarse del mercado laboral.

A pesar de ese sistema, el cálculo de las cuotas y de la edad de retiro parte también de la previsión de longevidad, es decir, de la cantidad de años que se espera que vivan las personas luego de la jubilación. Si estas "superan" esta previsión, se llega a lo que los actuarios llaman riesgo de longevidad, es decir, que las aportaciones sean insuficientes para cubrir una expectativa de vida cada vez más larga, sin aumentar edad de jubilación, porcentaje de contribución o cantidad de cuotas necesarias.

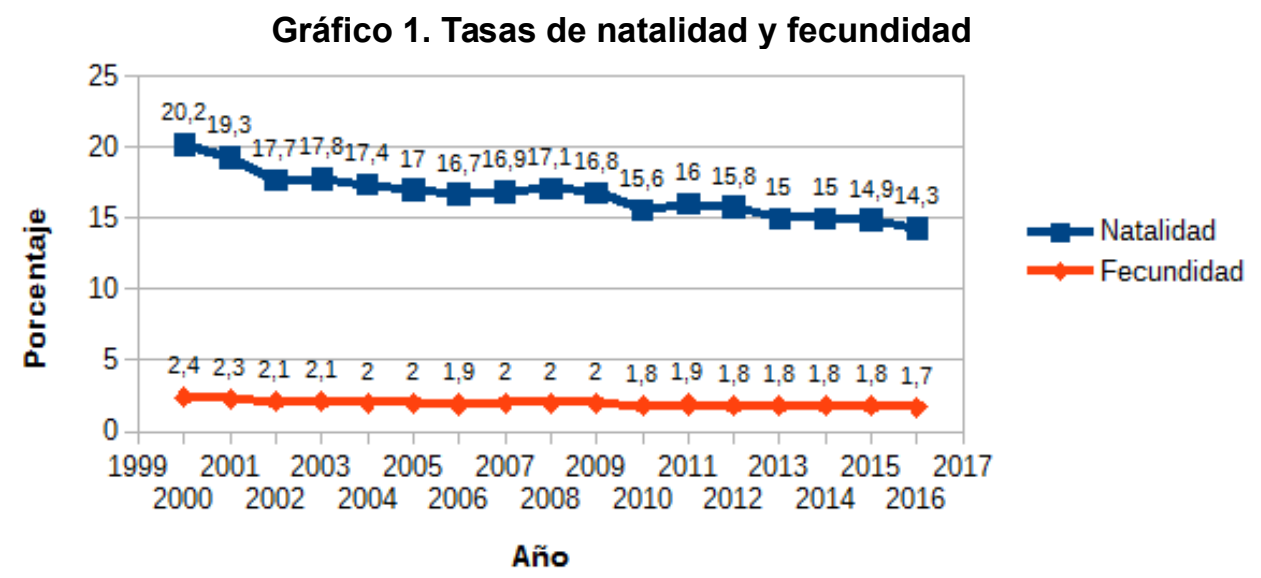

Elaboración propia con base en datos del INEC.

Sumado al radio de soporte, el cual es la relación personas económicamente activas cotizantes por persona jubilada es decreciente, lo que resulta de una 
inversión en la pirámide poblacional, es decir, cada vez tenemos menos hijos y vivimos más años. A su vez, esto implica una reducción en la fuerza de trabajo disponible, que trae consigo implicaciones importantes en la migración, dado que suelen ser más fecundos y jóvenes; por lo tanto, vienen a suplir necesidades de fuerza de trabajo, la productividad promedio del empleo y la rentabilidad de la cartera de inversiones del RIVM.

\section{Gráfico 2. Radio de soporte}

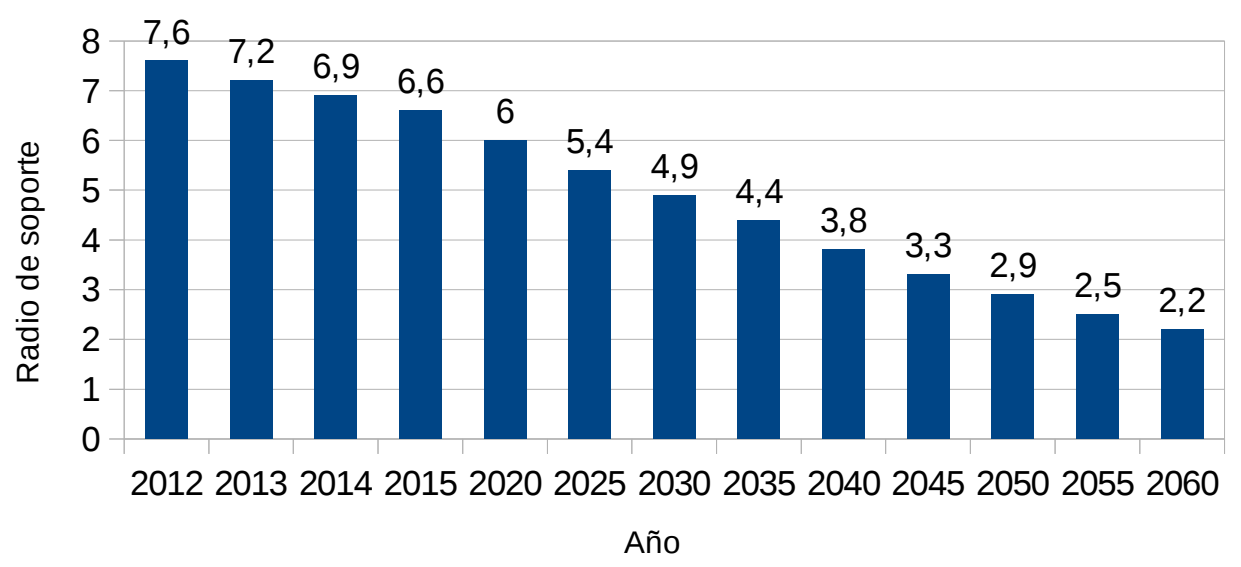

Eaboración propia con base en datos de Pérez Pérez y Torres Jiménez (2012)

Los datos en los gráficos anteriores sirven de evidencia para comprender la presión y la relación que provoca el aumento de la expectativa de vida y la disminución en la fuerza de trabajo, por razones de baja natalidad y de fecundidad, sobre las contribuciones necesarias para sostener al RIVM.

\section{El problema estructural del empleo durante el Proyecto Histórico Neoliberal}

El Proyecto Histórico Neoliberal (PHN) es la formulación teórica elaborada por Vargas Solís, véanse los trabajos: Vargas Solís (2011) y Vargas Solís (2015), como antítesis al proyecto desarrollista que tuvo Costa Rica durante los años de 1950-1970. El PHN atraviesa al menos tres fases: una primera, de 1984 a 1997, caracterizada por exportación y manufactura ligera de baja especialización; una segunda, de 1998 (llegada de Intel a Costa Rica) hasta el 2004, durante esta hay una manufactura de mayor especialización, se consolidan las hoteleras transnacionales y hay un aumento de las IED y las exportaciones de los regímenes de excepción o zonas francas. $Y$ finalmente una tercera, de 2005 a la actualidad, esta etapa es del capital financiero es- 
peculativo con grandes flujos de capitales de corto plazo, la salida de Intel en el año 2014 y el aumento de las presiones de empresas transnacionales sobre recursos naturales del país (oro, gas natural y petróleo).

Durante las casi tres décadas de implementación del PHN, las condiciones del empleo se han deteriorado, por ejemplo: el aumento de la informalidad y la productividad promedio del empleo. El principal problema con la informalidad es que la base de sostenimiento de la seguridad social costarricense son las contribuciones tripartitas; por lo tanto, un escenario de alta informalidad implica una fuerte disminución de los ingresos por las contribuciones de patronos y trabajadores. Aunque el desempleo sea relativamente "bajo", si su calidad no es alta o al menos formal, los sistemas de seguridad social son afectados.

La informalidad se refiere a la fuerza de trabajo que no contribuye a la seguridad social, debido a que no lleva una contabilidad formal, o bien porque no está inscrita con cédula jurídica ante el registro de la propiedad. Esto, a su vez, puede ser ilustrado comparando la productividad promedio de una persona trabajadora costarricense. En el cuadro 1, Costa Rica tiene la segunda posición de horas trabajadas en el mundo solo detrás de México, pero con una productividad muchísimo inferior a la de nuestro par chileno. Sin embargo, omitimos la comparación con países de alta productividad como Corea del Sur y los Estados Unidos, lo que podría ilustrar aún mejor la brecha de la productividad.

\section{Cuadro 1. Productividad promedio por hora trabajada para países de América Latina miembros de la Organización para la Cooperación y el Desarrollo Económico (OCDE)}

\begin{tabular}{lccc}
\hline País & $\begin{array}{c}\text { Producción por } \\
\text { trabajador (PIB en \$ } \\
\text { dólares } \\
\text { internacionales } \\
\text { constantes de 2011 } \\
\text { en PPA) estimación } \\
\text { al año 2015 (OIT) }\end{array}$ & $\begin{array}{c}\text { Promedio anual de } \\
\text { horas trabajadas por } \\
\text { trabajador al año } \\
\mathbf{2 0 1 5}(\text { OCDE) }\end{array}$ & $\begin{array}{c}\text { Producción por } \\
\text { trabajador/promedio } \\
\text { anual de horas } \\
\text { trabajadas }\end{array}$ \\
\hline México & 38246 & 2246,4 & \\
Costa Rica & 33764 & 2230,1 & 17,03 \\
Chile & 47627 & 1766 & 15,14 \\
\hline
\end{tabular}

Elaboración propia con base en datos de OCDE y OIT.

Una de los supuestos ideológicos del PHN indica que una de las ventajas comparativas de países como Costa Rica son los bajos salarios que paga en relación con los que tendrían que pagar en su país de origen, los cuales serían muchísimo más altos que la media salarial en el país destino. No obstante, la generación de empleo es reducida y la productividad promedio de personas trabajadoras es baja. A esto debemos sumarle los impactos de la crisis económica mundial del 2008 sobre la economía mundial y la estructura del empleo. 


\section{Gráfico 3. Porcentaje de empleo en condición de informalidad a partir del total} de la población ocupada

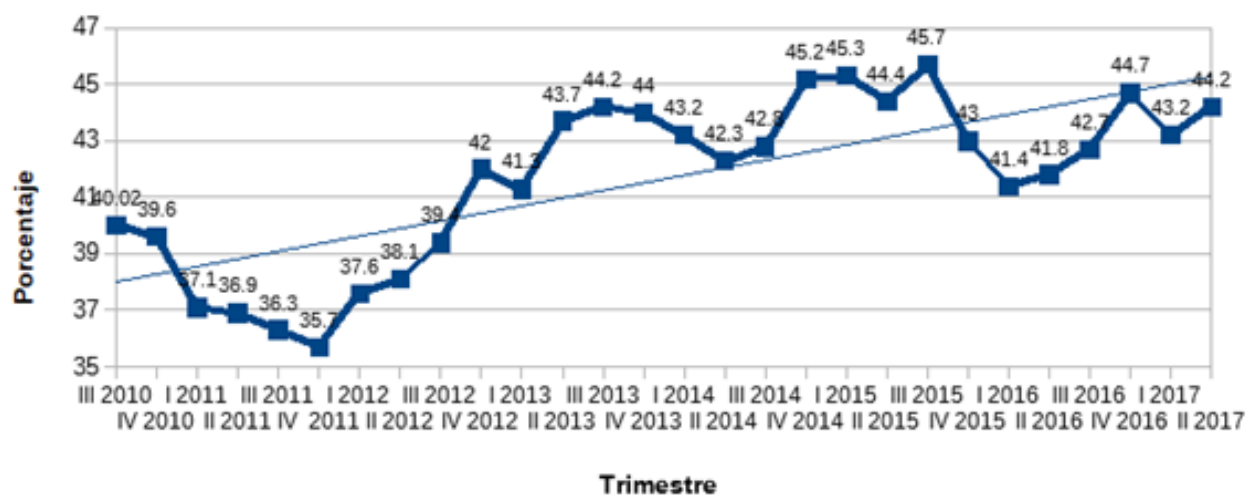

Elaboración propia con base en datos del INEC.

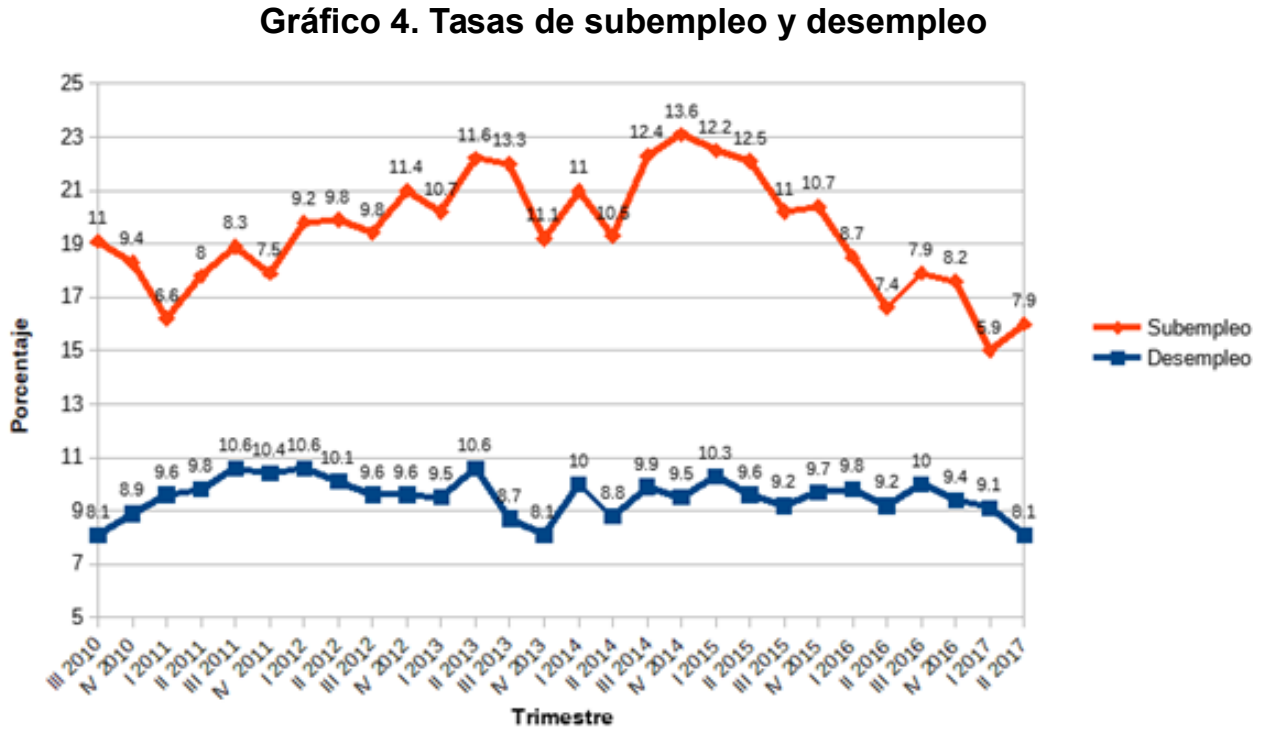

Elaboración propia con base en datos del INEC.

De los datos anteriores, se desprende que la estructura del empleo formal está debilitada y en condiciones de mayor precarización, lo cual tiene relación directa con las contribuciones. A su vez, la cantidad de empleo generado es tan importante como su calidad si deseamos mantener un sistema de salud y de pensiones robusto y financieramente estable. 


\section{El problema fiscal del país y la base tributaria insuficiente}

Desde aproximadamente 1970 hasta la actualidad, el Estado costarricense y los distintos Gobiernos han tenido que enfrentarse a un problema de carácter estructural y recurrente: el fiscal, como señala Vargas Solís (2015):

El problema de fondo tiene que ver con el debilitamiento progresivo de la base tributaria del Estado costarricense, que en parte muy importante es atribuible a la misma estrategia de desarrollo seguida, y en otra parte a la incrementada capacidad de los capitales y de los sectores más ricos, para evadir el pago de tributos, lo cual se ve favorecido por la incapacidad -o la falta de voluntad e interés, váyase a saber- de las autoridades económicas en los sucesivos gobiernos a lo largo de los últimos treinta años, para generar mecanismos más eficaces que permitan controlar el cumplimiento de sus obligaciones tributarias por parte de esos sectores económicos más poderosos.

La estrategia de políticas seguida ha debilitado la base tributaria por la multitud de exenciones que concede y los múltiples tributos suprimidos: exenciones a la inversión extranjera en zona franca y a la actividad exportadora y turística; tasas reducidas para las ganancias de capital; limitada tributación sobre herencias y patrimonios; insuficiente progresividad en los impuestos sobre ingresos y ganancias. Y, desde luego, toda la supresión de tributos sobre el comercio exterior, derivados de la opción ideológica asumida, de la adhesión al GATT y luego a la OMC y de los diversos tratados comerciales.

El debilitamiento progresivo de la base tributaria ha acarreado decisiones y mecanismos de búsqueda de financiamiento de la deuda del Estado, pues la atracción de IED, durante el PHN, aplica condiciones especiales las cuales 
favorecen que los grupos económicos más dinámicos, los vinculados al sector exportador, sean los que menos aportan al país porque su contribución se reduce a la seguridad social y a la generación de empleo.

Los distintos Gobiernos de turno, durante el Proyecto Histórico Neoliberal, han basado gran parte de su estrategia de desarrollo en la atracción de capitales de carácter transnacional, los cuales buscan esencialmente: 1) aumentar su rentabilidad y 2) el dominio de mercados. Estas dos condiciones encierran implícitamente una contradicción axiológica con las instituciones del bienestar aún existentes en el país (la Caja Costarricenses del Seguro Social, por ejemplo, y sus dos vertientes de aseguramiento: el Seguro de Salud y el Seguro de Pensiones) y sus principios de universalidad y solidaridad, dado que la contribución a la seguridad social se percibe como un costo asociado a la disminución de las rentas de los capitales transnacionales y, como señalamos, entra en contradicción con el punto 1.

A su vez, esa contradicción incluye otro problema: el elevado costo fiscal. La mayor parte de los capitales transnacionales se ubican en regímenes de excepción, conocidos como zonas francas, en los cuales se les exime del pago de impuestos con importantes subsidios por parte del Estado en infraestructura y electricidad. Esto se les brinda porque se persiguen dos intereses mayores: mejorar la balanza comercial y la generación de empleo; sin embargo, sobre el primero más bien ocurre lo contrario: “(...) se profundiza los problemas de la balanza comercial y balanza de pagos, ya que importa casi todo sus insumos y transfiere ganancias por montos superiores a los que ingresan al país" (Trejos París y Fernández Arias 2006, 35), y aumentan las importaciones, con el agravante de que no genera encadenamientos productivos.

Sobre el segundo interés mayor, los datos acerca del empleo que generan las zonas francas en el país muestran que este oscila entre el $2 \%$ y $3 \%$ de la fuerza de trabajo, es decir, entre los 60000 y los 80000 empleos de una fuerza de trabajo cercana a los 2000000 de personas. También, esto puede ser leído de la siguiente manera: aquellos sectores de mayor productividad, los vinculados con las exportaciones y los capitales transnacionales, son los de mayor riqueza; pero los que menos contribuyen al país, dadas las condiciones ventajosas en las que se encuentran.

Dichas condiciones tienden a explicar (sino totalmente, en gran parte) la necesidad de los distintos Gobiernos al endeudamiento y de buscar mecanismos para financiar su déficit, ya sea mediante la deuda interna, recurriendo a recursos de la Caja o a través de otros mecanismos de deuda externa. Un ejemplo de lo anterior es lo señalado por Badilla Solano $(2017,105)$ :

(...) la creación de la Autoridad Presupuestaria en el año 1982 ley número 6821 y la creación de la Ley para el Equilibrio Financiero del Sector Público número 6955 del año 1984. (...) le permitieron a la Autoridad presupuestaria someter a las instituciones autónomas, entre ellas la 
Caja, a una serie de directrices consistentes con las políticas de desarrollo señaladas por el Ejecutivo de turno, esto en complicidad con la Contraloría General de la República, la cual ordenaba las rebajas en los presupuestos para que coincidieran con lo establecido por la Autoridad Presupuestaria.

Las rebajas consistieron en implementar durante el periodo 1983-1999 de directrices que obligaron a la institución a utilizar el $10 \%$ del presupuesto de la CCSS en compras de bonos del Estado, hasta que la Sala IV, mediante el voto 7379-99 expediente 99-005906-0007-CO-V, determina la no obligatoriedad de este tipo de medidas para la institución.

Por su parte, los distintos Gobiernos de turno han utilizado diversos mecanismos de captación de recursos de la institución. Por ejemplo: los recursos arrebatados a la CCSS mediante el artículo 78 de la Ley de Protección al Trabajador 7983 (LPT de ahora en adelante); las deudas contraídas por el Estado por parte de la Ley 7374; y la retención indebida del impuesto sobre la renta.

El artículo 78 de la Ley de Protección al Trabajador (LPT) fue creado con la intención de fortalecer el financiamiento del RIVM y de extender la cobertura del sector no contributivo a partir de una aportación del $15 \%$ de las utilidades de las empresas públicas del Estado. Asimismo, la institución ha puesto en discusión la financiación de los recursos, ya que las utilidades de estas instituciones públicas son volátiles; por lo tanto, si estas exponen pérdidas, no se pueden cobrar, es decir, no son transferencias de las que se puedan tener seguridad total.

En este orden de ideas, no existe claridad sobre si el monto de los porcentajes de contribución de las instituciones públicas debe calcularse sobre las utilidades netas o por utilidades brutas. Esta segunda opción es la que se ha utilizado en los cobros respectivos. Por esta razón, el RIVM todavía no ha definido la distribución de los recursos, y esto se ha convertido en una estrategia por parte de las empresas públicas para no pagar sus obligaciones con el RIVM, lo cual ha provocado que su estabilidad financiera se vea afectada. En otras palabras, no ingresaron al régimen recursos importantes.

De acuerdo con la Dirección Actuarial CCSS (2017), el monto por cobrar del periodo 2013-2015 asciende a $\mathbb{W} 20$ 897,84 millones de colones, de los cuales se han logrado recaudar $\mathbb{l} 14313,52$ millones y, para el cobro del año 2016, se calcularon $\mathbb{l} 12194$ millones, de los cuales solo han ingresado $\mathbb{l} 3527 \mathrm{mi}-$ llones al régimen.

El incumplimiento del artículo 78 de LPT pone en duda dos cosas: primero, la posibilidad del RIVM de fortalecer y de extender su cobertura como un régimen de pensiones solidario cuyo objetivo es ser universal; y segundo, la res- 
ponsabilidad de las instituciones públicas de cumplir con sus obligaciones a la seguridad social del país, dado que la asignación de un $15 \%$ de sus utilidades es parte de un sistema que toma como prioridad el bienestar de los trabajadores pensionados y, para esto, es necesario un RIVM saludable.

El artículo 3 de la Ley 7092 indica que la CCSS goza de exoneración del impuesto sobre la renta al ser una institución autónoma del Estado. Sin embargo, el Ministerio de Hacienda ha retenido impuestos generados por títulos valores invertidos en el periodo de 1992-1995 que, según la Dirección Actuarial CCSS (2017), suman un monto de $\mathbb{Z} 2383438$ 346,03. La institución ha demandado al Estado por dichas retenciones, pero su solicitud ha sido rechazada a falta de pruebas y de caducidad de tiempo. También, durante el periodo 2006-2014, se ha retenido un monto aproximado de $\mathbb{L} 850158302,89$. Este incluye intereses moratorios, lo cual suma un total de $\mathbb{l} 1517334376,19$. Tales cifras son diferentes a las presentadas por ANEP (2017) y por Martínez Franzoni (2017). Es importante recalcar que la CCSS es una institución de salud. Entonces, cuando ocurre este tipo de situaciones, se le adjudican responsabilidades de cobranza que no tienen relación directa con sus funciones, sino a las instituciones encargadas de dichas responsabilidades. En este caso, corresponde al Ministerio de Hacienda que, como representante del Estado, ha tomado el doble papel de retener y de transferir los montos generados por los intereses y niega pagarlos con el motivo de la insuficiencia tributaria del Estado.

\section{La gestión de la administración y los mecanismos de control interno}

El acceso a una pensión digna y la estabilidad del régimen de pensiones son dos aspectos por considerar cuando se reevalúan las pensiones, puesto que los pensionados merecen una remuneración acorde a sus cotizaciones y el régimen requiere de equilibrio financiero para asignar dicho monto con la expectativa de garantizar el bienestar del pensionado.

El RIVM ha implementado, desde el 2013, una metodología de cotización creciente de la base mínima contributiva (BMC de ahora en adelante), que le permite a los trabajadores independientes y voluntarios contribuir, en función del mínimo, sus ingresos. Este tipo de metodología introduce distorsiones, pues trabajadores independientes reportan menos de sus ingresos para mantenerse sobre la BMC. Esto provoca que las cotizaciones de todos los contribuyentes no sean realmente justas porque quienes perciben un salario como trabajador dependiente sí cumplen con las contribuciones establecidas, mientras que los independientes utilizan mecanismos de elusión.

En este sentido, podría entenderse que, para los profesionales independientes, es más fácil no reportar sus ingresos reales, como lo indica OCDE (2017). Los pagos que reciben por sus servicios no son por medio de tarjetas 
de crédito o débito, tampoco emiten facturas por los cobros en efectivo (hasta este año 2018, en el cual se empieza a implementar la facturas digitales). Así resulta la posibilidad de declarar menos ingresos en comparación con lo que realmente ganan. Este tipo de evasión (no pago de las contribuciones a la seguridad social) y de elusión (reportar menos de subdeclaración o de elusión de las cargas reales) afecta las contribuciones a la seguridad social y a la recaudación tributaria del país.

A partir de tales actos, la institución desde el 2013 se ha propuesto igualar la base mínima contributiva con el salario mínimo legal del trabajador no calificado genérico de forma progresiva hasta llegar a $100 \%$ en el 2019 , con la expectativa de atraer más trabajadores independientes para extender la cobertura del régimen y detener la evasión y morosidad; pero al mismo tiempo, es importante preguntarse: ¿qué pasa con los trabajadores que perciben menos de un salario mínimo y desean contribuir a la seguridad social?, ¿con la nueva base mínima contributiva los profesionales independientes estarían cotizando lo justo acorde con sus ingresos?, ¿por qué no ha sido posible cruzar los datos de Hacienda, CCSS y la banca para captar a los evasores?

Ahora bien, el aumento de las pensiones mínimas del periodo 2005-2009 por encima de la inflación es producto de malos mecanismos de gestión, debido a que las revaluaciones de las pensiones mínimas fueron calculadas sobre estimaciones de inflación y de crecimiento de salarios con criterios técnicos no aprobados por la institución; esto pudo haber agregado más afectaciones financieras al régimen. El problema es que la institución todavía no posee una reglamentación con una metodología técnica para la revaluar pensiones, sino que se toman aspectos como el nivel de los salarios, los índices de precios, las estimaciones actuariales. En este sentido, el estudio actuarial de la UCR señala lo siguiente:

En el período de cinco años que va del 1/7/2005 al 1/7/2009 la PM se aumentó en promedio un $19,5 \%$ anual, el cual supera a la tasa promedio de inflación de 11,2\% del mismo periodo en 8,3 puntos porcentuales. Significa que durante ese periodo la PM se aumentó un $43 \%$ por encima del IPC. En el resto de periodos la PM creció levemente por debajo de la inflación de los precios. (Arias López, Barboza Chinchilla, y Ramírez González 2016).

Aunado a lo anterior, la implementación de Ley de Protección al Trabajador en el año 2000 aumentó la BMC acorde con el salario mínimo (SM de ahora en adelante). Este acuerdo se canceló en el 2006 y se retomó en el 2013. El estudio actuarial de la UCR indica que, durante el periodo 2006-2009, la BMC no se ajustó y provocó que se devaluara 39\% en relación con el SM: 
Como resultado de los altos aumentos en la PM y el estancamiento de la BMC, el monto de la PM llegó incluso a superar el monto de la BMC, lo que significa en muchos casos tasas de reemplazo superiores al 100\%. El monto de la BMC sobre el SM cayó de un $82 \%$ que tenía en 2006 a un 55\% en 2012, por debajo del valor de $66 \%$ que alcanzó en el año 2000. (Arias López, Barboza Chinchilla, Ramírez González 2016).

En el 2005, se implementan reformas reglamentarias para la solicitud de pensiones anticipadas y proporcionales a fin de garantizar la sostenibilidad del RIVM. La reforma del 2005 significó cambios en los porcentajes y en el número de cuotas. Un asegurado por vejez puede retirarse con pensión a los 65 años de edad y con 300 cuotas. Sin embargo, quien haya alcanzado esta edad y no cuenta con las 300 cotizaciones, pero sí con 180, tiene derecho a una pensión por vejez proporcional. Por otro lado, el trabajador asegurado puede anticipar su pensión con una pensión reducida con un castigo de $1,75 \%$ por cada trimestre adelantado. El requisito, en este último caso, es acumular 300 cuotas; a partir de los 62 años, para los hombres; y 60 años, en mujeres.

Las reformas significaron un alto crecimiento en la solicitud de las pensiones proporcionales y anticipadas en el 2006. Según la Dirección Actuarial CCSS (2017), la cantidad de pensiones por vejez proporcionales alcanzaron un crecimiento de $246 \%$ y; para las anticipadas, un $886 \%$, en comparación con las pensiones por vejez ordinaria con una tasa de crecimiento de $17 \%$. La pensión por vejez ordinaria del 2005 al 2012 supuso un gasto total de $\mathbb{l} 164761$ 083 080. Para la pensión por vejez proporcional significó un gasto de $\mathbb{l} 12$ 948712164,70 . Y para la pensión por vejez anticipada, un monto de $\mathbb{Z} 31$ 008707822,95 .

Las pensiones proporcionales y anticipadas representaron un alto costo para el RIVM en un momento de crisis financiera, dado que se realizaron con la estimación de que los trabajadores activos podrían cubrir a los pensionados (es decir, sobre un radio de soporte robusto). No obstante, como se mencionó, una estructura del empleo sumergida en la informalidad y subempleo, además del aumento de la población de la tercera edad acompañada de una disminución de la fuerza de trabajo, no permitió mantener tales suposiciones (la de un radio de soporte creciente). También, la institución no previó que las reformas tendrían un efecto de crecimiento tan alto de las pensiones proporcionales y anticipadas y su elevado costo.

Por otro lado, las inversiones del RIVM son importantes para su estabilidad financiera, ya que estas se convierten en mecanismos que aportan ingresos a la institución en medio de un contexto en el cual las contribuciones no son 
suficientes para mantener el régimen de pensiones; por lo tanto, las inversiones le permiten al RIVM mantener un sistema financiero estable. A su vez, la participación del RIVM en el mercado de créditos hipotecarios ha significado un aporte estratégico de recursos institucionales desde 1950. La Dirección Actuarial CCSS (2017) señala que el sistema de crédito hipotecario del RIVM significa $2,5 \%$ del total de sus inversiones, pero representa $1,7 \%$ en el sector de vivienda nacional, es decir, su participación está sujeta a movimientos de precios de mercado en los créditos hipotecarios del país.

Sumado a lo anterior, el Plan Escudo, de Óscar Arias, se presentó la siguiente medida para prevenir efectos negativos de la crisis financiera internacional: se les recomendó a las entidades que participaban en el mercado de crédito reducir en dos puntos porcentuales la tasa de interés de los créditos hipotecarios, cuya instrucción fue acatada por el Seguro de Pensiones; de lo contrario, la cartera hipotecaria del RIVM se hubiera visto en una posición de desventaja en un marco competitivo con las otras instituciones financieras del mercado nacional.

Al restablecer de nuevo los dos puntos porcentuales para el año 2011, la cartera hipotecaria del RIVM experimentó pérdidas en la inversión de sus recursos por razones de disminución o de cancelación de créditos y morosidad. De acuerdo con la Dirección Actuarial CCSS (2017), los créditos hipotecarios del RIVM pasaron de $\mathbb{l} 10265800$ 000, montos aprobados en el 2010 con 612 solicitudes aprobadas, a un total de $\mathbb{L} 4088300000$ de montos aprobados en el 2011 con 235 solicitudes aprobadas.

Con criterios de "legalidad", se efectúan inversiones en títulos valores con los cuales el Estado paga su deuda al Seguro de Salud. El Reglamento para la Inversión de las Reservas del Seguro de Salud, en su artículo 3, menciona que por razones de oportunidad frente a problemas de liquidez en el seguro de salud, se permite la venta de títulos valores del seguro de salud al Seguro de Pensiones en conformidad de la política de inversión.

Las transferencias de fondos indirectas entre el RIVM y SEM son permitidas, según las Normas Internacionales de Contabilidad autorizadas por la Contraloría General de la República, ya que estas se ejecutan mediante el mercado de valores. Los bonos con los que el Estado paga la deuda con el SEM se colocan en la Bolsa Nacional de Valores de Costa Rica y el RIVM los compra. Esto es una forma indirecta de transferir liquidez del RIVM al SEM. Sin embargo, la Dirección Actuarial CCSS (2017) señala que 30\% (《l16 420,9) de las inversiones del RIVM fueron títulos de valor comprados al seguro de salud por medio de puestos de bolsa autorizados; de igual forma, la economía del 2010 no fue la más favorable para la inversión en títulos valores para el RIVM. La compra de los títulos valores se realizó sin esperar puja en el mercado, lo que ocasionó que el RIVM no obtuviera mejores precios ni mejores condiciones para invertir.

El origen histórico de esta deuda tiene su razón en la creación de la Ley 7374, en la cual se le asigna al Fondo de Asignaciones Familiares (Fodesaf) 
la responsabilidad de contribuir a la seguridad social por la población en condición de indigencia, según lo establecido en los artículos 5 y 6 de dicha ley:

Artículo 5.- El Ministerio de Hacienda cubrirá, mediante el pago en efectivo, las obligaciones reglamentarias con la Caja Costarricense de Seguro Social. Para ello, deberán consignarse, en el Presupuesto Nacional de 1993, 1994, 1995 y 1996, los montos equivalentes al 65\%, 70\%, 85\% y $90 \%$, respectivamente, de dichas obligaciones reglamentarias, producto de su doble condición de patrono y de Estado como tal, con los Seguros de Enfermedad y Maternidad, Invalidez, Vejez y Muerte, así como las cuotas correspondientes a la atención de los indigentes y del sistema penitenciario, protegidos por los mencionados seguros. Las sumas no cubiertas, hasta alcanzar el ciento por ciento de las obligaciones reglamentarias en los años antes anotados, se cancelarán en esos mismos años, mediante mecanismos de pago, según convengan las partes. A partir de 1997, la asignación presupuestaria y el correspondiente pago en efectivo deberá alcanzar el ciento por ciento de las obligaciones citadas.

Artículo 6.- El costo de atención de la población indigente se cubrirá con los recursos provenientes de las partidas del Fondo de Asignaciones Familiares, para lo cual se utilizará como referencia el porcentaje de cotización media, calculado por la Dirección Técnica Actuarial de la Caja Costarricense de Seguro Social.

Sin embargo, a partir del año 1994, el Ministerio de Hacienda, bajo la administración de Figueres Olsen, reduce el presupuesto asignado a Fodesaf, de manera que esta instancia no pudo contribuir a la CCSS por cuenta de la población en condición de indigencia, debido a la ausencia de la partida presupuestaria necesaria para realizar la contribución. Esto provocó una deuda acumulada, correspondiente al periodo 1994-2007 (13 años de deuda), de 
$\mathbb{Z} 301000$ millones entre el monto principal y los intereses (Herrera 2012), lo cual lleva al Estado a buscar convenios de pago con el Seguro de Salud.

Ese convenio de pago se hace a través de bonos del Estado con los que se trata de saldar la deuda, el cual, como señalamos en párrafos anteriores, coloca los bonos en la bolsa de valores y es el Seguro de Pensiones el principal comprador, el $90 \%$ de las inversiones están concentradas en bonos del Estado. Por una parte, si bien esto no representa ninguna ilegalidad, es un mecanismo indirecto de transferencia de recursos de pensiones hacia salud. Por otra parte, como señala Badilla Solano $(2017,79)$,

(...) el régimen corre el riesgo de concentración dado que cerca del $90 \%$ de sus inversiones tienen relación con el Estado. El grueso de la cartera de inversiones en el corto y en el largo plazo se concentran en bonos del Estado(...) A su vez el hecho de que gran parte de la cartera de inversiones se concentre en bonos del Estado, constituye una forma de transferir recursos de las pensiones hacia las necesidades del Estado y de financiar el déficit del Gobierno, aunque debemos señalar que la concentración no es necesariamente negativa, aunque sí insuficiente para satisfacer las necesidades del régimen. En otras palabras, el régimen ha sido utilizado como caja chica del Estado para transferir recursos hacia el seguro de salud y bien para solventar necesidades del Gobierno central, Hacienda y el Banco Central, a través del mecanismo de bonos.

Quizás una de las alternativas ante el riesgo de concentración y de mejorar la rentabilidad de las inversiones es la inversión en obra pública. Esta tesis ha sido esbozada por el Banco Central de Costa Rica (BCCR) y por la Superintendencia de pensiones (SUPEN) (2014), la cual ha señalado que el principal obstáculo es el de la creación de los mecanismos financieros para que el Régimen acceda a la inversión en obra pública. Sobre este punto Badilla Solano, $(2017,82)$ señala:

(...) el principal obstáculo para que el seguro de pensiones pueda invertir en infraestructura es la ausencia de los mecanismos financieros que lo permitan, por ejemplo en 
el caso de la construcción de la carretera a San Ramón, el Gobierno tuvo que promulgar la Ley 9292 Desarrollo de obra pública corredor vial San José-San Ramón y sus radiales, mediante fideicomiso de febrero del 2015.

Por su parte el BCCR y la SUPEN, señalan que:

(...) la rentabilidad de un activo de infraestructura es del $9,3 \%$, que lo sitúa favorablemente en comparación con los bonos $(5,2)$, las acciones $(8,1 \%) \mathrm{e}$, incluso, los fondos de capital privado. Por otra parte, la volatilidad de los activos de infraestructura $(7,9 \%)$ es menor que la de un fondo inmobiliairio $(9,5 \%)$, inclusive está por debajo del fondo de capital privado (30,2\%). El perfil de riesgo de la inversión en infraestructura se encuentre entre el de bonos y el de acciones, lo que hace justamente que su relación relación riesgo-rendimiento sea mejor (muy cercana a los bonos) y que genere rentabilidades mayores. (BCCR y SUPEN 2014).

Por último, la insuficiencia de ingresos que se reporta en el Seguro de Pensiones, a partir del año 2009 , significa un momento crítico para la cobertura de los gastos operativos del régimen. La Dirección Actuarial CCSS (2017) indica que, con una diferencia de ingresos y gastos de $\mathbb{U} 19067$ millones en el 2009; de $\mathbb{l} 62$ 894,6 en el 2013; de $\mathbb{L} 83$ 676,6 en el 2014; y de $\mathbb{L} 2143,8$ para el 2015, la administración, con criterios "técnicos" y de "legalidad" plantean la necesidad de requerir el uso de intereses de la reserva para cubrir pagos de pensiones y de aguinaldos como gastos operativos.

Dado que el RIVM ha experimentado durante años un debilitamiento de los ingresos sobre los gastos, la institución se ha propuesto buscar nuevas formas de asegurar ingresos al RIVM, a fin de mantener su equilibrio financiero a flote por medio de "alternativas a corto plazo", por ejemplo: el aumento del $1 \%$ al trabajador, tomando en cuenta que la carga recae en los salarios de las personas trabajadoras. 


\section{Acerca de los alcances y limitaciones de este artículo}

Todos los estudios actuariales señalan que, a mediano plazo, el régimen es insostenible; por lo tanto, es necesario pensar en nuevas alternativas de financiamiento (véase el cuadro 2). Como se explicó, el RIVM se ha debilitado por factores externos e internos que han provocado su crisis financiera, en un contexto en el cual la población de la tercera edad crece, el radio soporte de los trabajadores a largo plazo no podrá sostener las pensiones de los asegurados debido a la disminución de la fuerza de trabajo. A su vez, la estructura del empleo formal está debilitada por la informalidad y el estancamiento del subempleo; las mujeres y los jóvenes son los más afectados por la informalización de la fuerza de trabajo. Además, no solo se trata de crear más empleo, sino que este sea de calidad, es decir, con una mejor productividad y en condiciones de formalidad.

\section{Cuadro 2. Año crítico según escenario y valuación del RIVM}

\begin{tabular}{lcccccc}
\hline \multicolumn{1}{c}{ Escenario } & $\begin{array}{c}\text { OIT } \\
\mathbf{2 0 0 5}\end{array}$ & $\begin{array}{c}\text { Nathal } \\
\mathbf{2 0 0 7}\end{array}$ & $\begin{array}{c}\text { OIT } \\
\mathbf{2 0 0 8}\end{array}$ & CCSS 2008 & CCSS 2010 & $\begin{array}{c}\text { Escuela } \\
\text { Matemática- } \\
\text { UCR }\end{array}$ \\
\hline $\begin{array}{l}\text { Contribuciones } \\
\text { insuficientes }\end{array}$ & 2011 & 2015 & 2028 & 2027 & 2011 & \\
$\begin{array}{l}\text { Ingresos totales } \\
\text { insuficientes }\end{array}$ & 2022 & N.D. & 2038 & 2037 & 2038 & $2022-2028$ \\
$\begin{array}{l}\text { Reservan se } \\
\text { agotan }\end{array}$ & 2028 & 2023 & 2044 & 2042 & 2042 & $2027-2034$ \\
\hline
\end{tabular}

Elaboración propia con base en Robles Cordero (s.f.) y en Arias López, Barboza Chinchilla y Ramírez González (2016).

Por otro lado, la deficiencia tributaria del Estado le ha costado importantes cifras al RIVM, dado que el Estado es el principal deudor del seguro de salud y el RIVM. Este se ha encargado de utilizar mecanismos de evasión para saldar sus deudas con recursos pertenecientes a ambos seguros. Asimismo, el papel de control interno de las diferentes autoridades de la institución en la toma decisiones reconocen la urgencia de fortalecer las finanzas del RIVM por medio de reformas y de modificaciones que contribuyan a salvaguardar la crisis del sistema. Por estas razones, es necesario observar la crisis de pensiones como un problema colectivo y no como un problema solo de los trabajadores; una nueva mirada a las pensiones es básica para alcanzar y mantener un sistema de pensiones estable que garantice pensiones dignas en el presente y en el futuro. 


\section{Bibliografía}

ANEP. 2017. "¿Por qué el IVM está en crisis? Aquí se lo explicamos». ANEP TV. Costa Rica. https://www.youtube.com/watch?v=FeQ8Dsyvgz8.

Arias López, Rodrigo, Luis Alberto Barboza Chinchilla y José Alexander Ramírez González. 2016. "Estudio actuarial del seguro de invalidez, vejez y muerte administrado por la CCSS. (Con corte al 31 de diciembre del 2015)». San José, Costa Rica: Escuela de Matemáticas de la Universidad de Costa Rica.

Badilla Solano, Andrey. 2017. Informe de investigación: Orígenes políticos y económicos de la crisis de la CCSS. Una explicación general. San José: Universidad Estatal a Distancia de Costa Rica. Disponible en https://investiga.uned.ac.cr/cicde/index.php/informes-deinvestigacion/207-ccss

Banco Central de Costa Rica, y Superintendencia de pensiones. 2014. «Acceso de los fondos de pensiones al financiamiento de obra pública». Comunicaciones Milenio. Acceso el 22 de octubre de 2018. https://www.supen.fi.cr/documents/10179/19821/Acceso+de+los+fondo s+de+pensiones+al+financiamiento+de+obra+p\%C3\%BAblica.

Dirección Actuarial CCSS. 2017. «Oficio 49532-2017: Atención Acuerdo de Junta Directiva relacionado con Régimen de IVM.» Costa Rica: CCSS. Acceso el 22 de octubre de 2018. http://www.ccss.sa.cr/pensiones/docs/49532.pdf

Herrera, Jorge. 2012. "Informe sobre el caso de la Caja Costarricense del Seguro Social». Asesores de fracción PAC. San José, Costa Rica.

Martínez Franzoni, Juliana. 2017. «La Verdad Incómoda del IVM». ANEP TV. Costa Rica. Acceso el 22 de octubre de 2018. https://www.youtube.com/watch?v=zYXv7A7d9lo.

Martínez Franzoni, Juliana y Diego Sánchez Ancochea. 2016. The Quest for Universal Social Policy in teh South: Actors, Ideas, and Architecures. 1era ed. New York: Cambridge University Press.

OCDE. 2017. Análisis de políticas fiscales de la OCDE: Costa Rica 2017. Paris.: OECD Publishing, Acceso el 22 de octubre de 2018. http://www.oecd-ilibrary.org/taxation/analisis-de-la-politica-fiscal-de-laocde-costa-rica-2017 9789264278608-es.

Pérez Pérez, Olger, y Cristian Torres Jiménez. 2012. «Valuación actuarial de largo plazo del seguro de pensiones de invalidez, vejez y muerte (con corte al 31 de diciembre del 2011)». Dirección Actuarial-CCSS.

Robles Cordero, Edgar. S.f. «Regímenes de Pensión: Situación y Perspectivas en España y Costa Rica». Super Intendencia de Pensiones. Acceso el 22 de octubre de 2018. 
http://www.uned.ac.cr/posgrado/images/cong_derecho/Ponencias/2_Ed gar_Robles_Cordero.pdf .

Trejos parís, Maria Eugenia y Mario Fernández Arias. (Eds). 2006. Tratado de libre comercio: Estados Unidos-Centroamérica-República Dominicana: estrategia de tierra arrasada. 1era ed. San José, Costa Rica: EUNED.

Vargas Solís, Luis Paulino. 2011. «Costa Rica: Tercera fase de la estrategia neoliberal. Contradicciones y desafíos (2005-2010)». Revista Rupturas 1 (1): 84-107. Acceso el 22 de octubre de 2018. http://investiga.uned.ac.cr/revistas/index.php/rupturas/article/view/144

Vargas Solís, Luis Paulino. 2015. «El Proyecto Histórico Neoliberal: Su devenir histórico y su crisis. Conferencia Perspectivas del modelo de desarrollo en Costa Rica. Universidad Nacional, 22 de setiembre 2015. 